\title{
A COMPANHEIRA MARIA
}

\section{Em tempos de Candelárias, Carandirus, Eldorados dos Carajás, Diademas não dá para apagar da memória o que significou a tortura e a Ditadura Militar}

Para Heleni Telles Guariba, Iara Yavelberg, Sônia Angel, Helenira Rezende Nazaré e todas as companheiras Marias assassinadas pela ditadura militar...

"Bom, eu sou a companheira Maria, membro da direção do Movimento Revolucionário 8 de Outubro, o MR-8... O MR-8 é uma organização com muitos serviços prestados contra a ditadura militar no Brasil..." Com roupa escura, estilo militar, cabelos curtos e braços para trás, a companheira Maria surge por detrás de uma parede do aparelho em que se reúnem os noviços da luta armada e entra na ação de $\mathbf{O}$ que é isso, companheiro?, o filme mais polêmico do cineasta Bruno Barreto.

A primeira imagem, masculinizada, e a primeira sentença - a reproduzida acima formam a caricatura de uma militante revolucionária dos anos 60 no Brasil. A companheira Maria, com a sua entrada em cena, e

\section{O AUTOR}

\section{Izaías Almada}

Jornalista, escritor e roteirista. Autor de: A metade arrancada de mim, $O$ medo por trás das janelas, Florão da América, Memórias emotivas; do roteiro do filme Sinais de fogo e da peça Uma questão de imagem. Foi prisioneiro da ditadura militar entre 1969/71. no entender do roteirista Leopoldo Serran, transforma a militância revolucionária num talão de notas fiscais por serviços prestados contra a ditadura, cuja cobrança se quer fazer agora, quase trinta anos depois, através de análises ou interpretações superficiais como é a do próprio filme. A imagem é significativa e bastante reveladora de como o Brasil deste final de século, neoliberal e venal, pensa e vê a oposição política, posta na ilegalidade, no Brasil de trinta anos atrás.

Ao contrário de certa crítica que saudou o filme como sendo um olhar maduro, equilibrado e cordial ( sic) do Brasil/90 sobre o violento e sectário Brasil/60,

O que é isso, companheiro? é, na verdade, uma visão fernandohenriqueana e collorida daquele período, isto é, uma visão desgostosa, arrependida, elitista e, ao mesmo tempo, arrogante sobre o que aqueles anos significaram para milhares de jovens no Brasil, durante a ditadura militar.

Jovens, muitos deles, que morreram por um ideal em que acreditavam sinceramente e que - ao contrário do que se pretende afirmar - não eram ingênuos ou manipulados por militantes mais velhos. A esse propósito, chega a ser grotesca, no filme, a presença da personagem Toledo, o cidadão brasileiro Joaquim da Câmara Ferreira. Seria ele a ilustração visual de um manipulador? Primário. Quer do ponto de vista dra- 
matúrgico, pois a personagem entra mudo e sai calado, sem qualquer informação que nos ajude a compreender porque ele estava ali, naquele momento, fazendo alguma coisa... Quer do ponto de vista de caracterização, já que a figura de Toledo no filme nos lembra muito o comediante Zé Trindade das chanchadas da Atlântida...

Mas atenção: não se trata aqui de uma reação emocional, de um retesamento ideológico contra os erros de avaliação e interpretação histórica dos autores do filme. Muito já se escreveu a respeito. Isso, em determinadas circunstâncias até (como a reivindicada e propagandeada liberdade de criação por parte dos produtores), pode não ser relevante, embora o ponto de vista que se assume em questões políticas termine sempre por ser uma escolha ideológica. É mais que isso: para além das incoerências já apontadas em outras críticas e artigos, o filme é preconceituoso.

Preconceituoso em relação a uma suposta e inconsciente rivalidade entre paulistas e cariocas; preconceituoso em relação ao saber e não saber falar inglês; preconceituoso com a origem de classe de alguns personagens, mais evidente no conflito Paulo versus Jonas e, por último - mas não menos importante - preconceituoso também em relação às mulheres.

Vamos lá ver: a companheira Maria (Fernanda Torres) é apresentada como sendo uma liderança do MR-8 até o momento da expropriação bancária feita pelo grupo a que pertence. Com a chegada dos paulistas Jonas (Matheus Machtergaele) e Toledo (Nelson Dantas) - ela assume, nas suas atitudes e no seu discurso, total subserviência à maior experiência política e militar dos companheiros mais velhos, homens. Passa a um segundo plano na ação dramática e política, voltando apenas em alguns momentos para chorar, rediscutir superficialmente a opção do grupo e a sua, pessoal, além de fazer sexo com o companheiro Paulo (Pedro Cardoso), talvez um desvio pequeno-burguês da companheira Maria. Mais próximo, do que imagina, à visão militarista da época que quer criticar, o filme de Barreto solfeja - em muitas das suas cenas - na clave de que todo revolucionário deveria ser macho, inclusive as mulheres. Visão dos anos 90 . O contraponto usado, a personagem Paulo, é frágil demais para desmontar a premissa. Quando me lembro das companheiras com quem convivi e militei, não posso deixar de rir do clichê.

A rigor, todo o filme situa-se no perigoso e movediço terreno da caricatura, uma vez que os autores - receosos de trabalharem com estereótipos - forçaram a mão noutra direção, caindo na própria armadilha. Evitaram o maniqueísmo comportamental, de atitudes, filosófico se quiserem, com o propósito bem intencionado de verticalizar (humanizar) esse ou aquele personagem e foram surpreendidos por outro tipo de maniqueísmo, mais sutil: o ideológico. Não é difícil destacar no filme, entre outras, a seguinte proposição: o militarismo revolucionário de esquerda era mau, calculista, frio (Jonas ameaça matar companheiros indecisos e torturar o embaixador Elbrick); sua contrapartida, a repressão policial-militar, uma política do estado brasileiro na altura, sofre de angústias diante do ofício da tortura. Logo, leia-se: só as pessoas de boa índole têm problemas de consciência diante dessas situações limites. De um lado, a possibilidade da tortura, subjacente ao comportamento de Jonas, o bandido da luta armada. De outro, a tortura como um mal menor, um dilaceramento da alma por dever de ofício, o xerife da repressão. 
Segundo Bruno Barreto, ele evitou fazer um filme de mocinhos e bandidos, como seria do agrado da esquerda. É tão ingênuo o silogismo, que temos o direito de pensar que se trata de um maniqueísmo às avessas daquele que Bruno Barreto critica para defender sua intrepretação estética de um fato político contundente. Ou é apenas calhordice e não há aqui nenhuma ingenuidade...

Mas, voltemos à nossa tese: apesar do cenho franzido e do uniforme militar (copiado de uma famosa foto do capitão Lamarca a ensinar tiros aos seguranças do Bradesco) e da dureza do discurso inicial, ainda assim é a companheira Maria que prepara o intragável rango revolucionário dentro do apartamento em que se escondem, sendo criticada por isso com ironia. Lugar de mulher - mesmo a guerrilheira - é na cozinha. Assim como René (Glória Abreu), a outra guerrilheira, é quem lava a camisa do embaixador, porque também o tanque é local apropriado para as mulheres. Como se vê, nos serviços prestados contra a ditadura, os revolucionários socialistas continuavam a esperar das companheiras o mesmo desempenho e papel que, por suposto, traziam de seus lares pequenos-burgueses... A ação dramática vai caminhando de preconceito em preconceito.

Primeira a duvidar da validade da própria ação de expropriação bancária que acabaram de realizar, porque as mulheres são inconstantes e têm um sexto sentido (a observação é minha), a companheira Maria faz a apresentação dos dois chefões vindos de São Paulo para o resto do grupo. Com um discurso que prima pelo lugar comum e pela inverossimilhança, destaca-lhes o curriculum na luta durante a guerra civil espanhola (Toledo), e em operações arriscadas na capital paulista (Jonas), para finalizar com essa pérola: "Bem vindos ao Rio de Janeiro, companheiros, e que a nossa missão se cubra de sucesso". Eta falinha danada! Há sempre um ar solene e formal em muitas das falas, como se fazer a revolução fosse uma questão de oratória e de geografia. Os hardboys da Rua Maria Antônia são apresentados aos young-boys do cine Paissandu que, num alegre convescote revolucionário, irão juntar suas forças para a prestação de mais um serviço contra a ditadura, seqüestrando o embaixador do país mais rico do mundo. Se eu não tivesse visto, eu não acreditaria. $\mathrm{O}$ que é isso, companheiros? Ficção, acima de tudo, ficção! Na abertura, o letreiro já avisa que os personagens não são os mesmos da história real, que alguns são a fusão de dois ou mais participantes da história verdadeira... Trata-se, pois, de uma meia ficção? Assim como de uma mulher meio grávida? Ou de um meio anão?

Continuando: a ação precisa avançar, como mandam os cânones da dramaturgia cinematográfica. O seqüestro do embaixador americano precisa ser preparado e, nessa preparação, a companheira René cumprirá a difícil tarefa de obter informações sobre a segurança do diplomata. Uma tarefa arriscada, de astúcia, coragem, dissimulação, inteligência. Pouco disso se vê. Esses atributos, embora parte da natureza humana, não serão suficientes para humanizar a personagem. Como se trata de uma mulher, e bonita, que tal ela conseguir as informações na cama, assim como uma Mata-Hari tropical? É mais atraente, mais comercial. Isto irá condizer mais com a natureza feminina, o envolvimento pela sensualidade, a conquista pelo sexo. Ingênuo, é verdade, até porque a cena da cama é apenas insinuada. Mas, no fundo, aquele mesmo tipo de raciocínio que diz da mulher estrupada: "alguma ela aprontou!" Clichês. E eles vão por aí afora... 
Como não existe uma memória da História brasileira contemporânea, o que fica para as gerações mais novas é a versão do filme sobre a maneira de ser e agir dos guerrilheiros urbanos, aqui não importando se essa versão é ficcional ou não. Em entrevistas que deu à imprensa, Bruno Barreto tentou se demarcar de compromissos com a ditadura militar brasileira. Não precisava chegar a tanto, pois todos sabemos que era ainda adolescente quando tudo se deu. Não se trata aqui também de crucificar o cineasta por um compromisso que ele, de fato, não tem. Mas por isso mesmo o diretor e seu roteirista deveriam ter tomado alguns cuidados na elaboração do roteiro (bem armado na sua estrutura dramática), maior atenção na pesquisa feita, para que não desabasse sobre o filme a suspeita de que ele faz a maquiagem da ditadura. A arte tem dessas surpresas: nem sempre aquilo que mostra vai significar a vontade, a subjetividade do autor. A realidade é multifacetada e nos prega peças umas atrás das outras. $\mathrm{O}$ sofrimento do embaixador Elbrick é muito mais explorado no filme do que o sofrimento dos presos, torturados e mortos. Por quê? Essa é uma opção estética? Ou ideológica?

Há um discurso calhorda por aí que prega a inutilidade de se falar nesses assuntos, como a tortura, por exemplo, de reabrir essas feridas. Porque o Brasil está noutra, pronto a se transformar em grande potência, pronto a marcar presença entre as nações civilizadas. Será? E a Candelária? E Diadema? E o Carandiru? E Eldorado de Carajás? E os precatórios? E a compra de votos para a reeleição presidencial? Quem reabre as feridas, aliás, é o próprio filme de Bruno Barreto, com sua parcialidade, sua maneira estética de tratar a política...

\section{MAQUIAR A DITADURA}

Raciocinemos juntos: se Jonas é o guerrilheiro brutal, impiedoso, disposto a matar o primeiro que vacilar e o policialtorturador é apenas um oficial da Marinha que cumpre angustiado com o seu dever, que conclusão devo tirar da frase "Se essa escória chegar ao poder, não vai haver tortura, mas o fuzilamento sumário" dita pelo policial à sua mulher de baby-doll? A resposta é simples: naquelas circunstâncias, a tortura seria justificável, senão a escória (Jonas e seus companheiros) poderiam chegar ao poder e fuzilar indistintamente aos seus eventuais opositores. Só que a História se encarregou de mostrar (e aqui não há opção estética que resista) que o embaixador Elbrick saiu livre do seu cativeiro de pouco mais de 96 horas, enquanto o corpo de Virgílio Gomes da Silva nunca foi encontrado... Mas o Jonas do filme não é Virgílio Gomes da Silva, exclamarão pela centésima vez os autores do filme! E o embaixador Elbrick, quem será? Eisenhower? Cyrus Vance? Bill Clinton?!... Nenhum deles? Faça um $\underline{X}$ na resposta certa.

Nada, em nenhuma circunstância, justificará a tortura. Será sempre um ato covarde, abjeto, desumano. E evitar mostrar cenas de tortura (as que estão no filme são um arremedo do que se passou) também terá sido uma opção estética de $\mathbf{O}$ que é isso, companheiro?, pois tais cenas chocam, intimidam, podem esfriar o espectador em relação à narrativa dramática, não dão bilheteria. Mas não há como separar a tortura da ditadura militar brasileira: uma coisa está intimamente ligada à outra. Evitar o assunto, em filmes dessa natureza, é tampar o sol com a peneira, não é ser cordial. Quando muito, hipócrita, porque a tortura continua sendo praticada em nossas delegacias e pre- 
sídios. Filmar uma cena de tortura de forma realista, em toda sua crueza e boçalidade, se bem realizada e integrada à ação, no caso ao conflito principal da narrativa, é lutar pelo respeito aos direitos humanos e contra a barbárie. Não há que ter receios. Assim o entenderam Roberto Farias em Pra frente Brasil, Luís Sérgio Person em $\mathbf{O}$ caso dos irmãos Naves, Costa-Gavras em $\mathbf{Z}$, para ficar com alguns poucos exemplos.

$\mathrm{O}$ que os olhos não vêem, o coração não sente, diz o ditado. O cinema, pela força da imagem em movimento, é talvez a relação mais simples, direta e impactante - em arte - dos olhos com o coração. De alguma maneira, tudo o que se imprime, se exprime. Ou não? Quando a companheira Maria surge, agora no final, imobilizada em sua cadeira de rodas, o filme faz uma elipse em sua ação dramática. A elipse cinematográfica faz avançar a ação deixando de lado aquilo que não tem muita importância ou realçando as consequiências da ação anterior sem the destacar os pormenores, ocultandoos. Stanley Kubrick em 2001 - Uma odisséia no espaço mostra um macaco jogando um osso para o alto, que gira em câmera lenta e se funde com uma nave espacial, numa das elipses mais famosas da história do

Resumo: Crítica do filme $\mathbf{O}$ que é isso, companheiro?, de Bruno Barreto. Nela o autor aponta, para além das incoerências dramatúrgicas e históricas, o preconceito com que o filme trata a mulher. Para o autor, o filme mostra um maniqueísmo às avessas, na tentativa de maquiar a Ditadura Militar brasileira e a tortura aos presos politicos.

Palavras-chave: $\mathbf{O}$ que é isso, companheiro?, preconceito, filme, Bruno Barreto cinema. Nela, em poucos segundos, Kubrick exprimiu magistralmente sua idéia sobre a evolução do homem e de humanidade. Em seu filme, Barreto mostra o protagonista, em plano fechado, naquilo que se supõe seja o temível pau-de-arara e, numa panorâmica que desenquadra o personagem buscando o fundo escuro, deixa-nos com seu grito de dor. Em seguida, vemos surgir Maria em cadeira de rodas. Também uma elipse, uma elipse temática, mas aqui encobrindo aquele que talvez pudesse ser o momento mais digno de sua principal personagem feminina, que a resgataria como personagem, militante de oposição à ditadura $\mathrm{e}$ como mulher. E que também resgataria o filme dos preconceitos exibidos. Ao contrário: Maria é conduzida lentamente pela pista em direção à aeronave que levará mais um grupo de prisioneiros políticos para fora do país. Dessa vez setenta, em troca de um embaixador alemão. Todos, nós espectadores, e cada um dos seus companheiros, olhamos para ela com comiseração e um nó na garganta. O que fizeram com esse ser frágil, desprotegido, com essa mulher? Somos convocados à piedade, o sentimento do preconceito, quando - na verdade - deveríamos olhar a cena com revolta e orgulho...

Abstract: Critical review of the film $\mathbf{O}$ que é isso companheiro? (What is this companion?), by Bruno Barreto. In this critique the author points out, over and beyond dramaturgical and historical inconsistencies, the biases the film has towards women. For the author, the film presents inside out manicheism in an attempt to give the Brazilian Military Dictatorship and political prisioner tortures a face-lift.

Keywords: $\mathbf{O}$ que é isso companheiro? (What is this companion?), biases, film, Bruno Barreto 